\title{
The Effect of Moisture and Fine Grain Content on the Resilient Modulus of Sandy Clay Embankment Roadbed
}

\author{
Nguyen Anh Tuan \\ Faculty of Transportation Engineering \\ Ho Chi Minh City University of Transport \\ Ho Chi Minh City, Vietnam \\ tuanna@ut.edu.vn
}

\author{
Phan Quang Chieu \\ Faculty of Civil Engineering \\ Tien Giang University \\ Tien Giang, Vietnam \\ phanquangchieu5@yahoo.com
}

\begin{abstract}
This paper studies the effect of moisture and fine grain content on the resilient modulus of sandy clay embankment roadbed in the Mekong Delta, Vietnam. The study analyzed the grain content of 30 soil samples on the annually flooded routes of the Mekong Delta according to the AASHTO T88-97 standard. The triaxial compression test at room temperature was used to estimate the resilient modulus of the samples belonging to 6 moisture levels. The experiments were conducted using 3 levels of lateral pressure, 0,21 , and $41 \mathrm{kPa}$. Five deflection stress tests of $14,28,41,55$, and $69 \mathrm{kPa}$, were conducted for each lateral pressure. The results showed that as the percentage of grains finer than $0.075 \mathrm{~mm}$ increased, the variation ratio of the resilient modulus also increased. The content of grains finer than $0.075 \mathrm{~mm}$ was between $54.1 \%-93 \%$, while the variation ratio of the resilient modulus ranged between $53.7 \%$ and $89.1 \%$. Moreover, as the percentage of grains finer than $0.075 \mathrm{~mm}$ increased, water absorption capacity increased and resilient modulus decreased. As moisture and fine grain content influence the resilient modulus of the roadbed, this study's results will help to limit and prevent the erosion of sandy clay embanked roadbeds, especially on frequently flooded areas such as the Mekong Delta.
\end{abstract}

Keywords-resilient modulus; moisture content; fine grain content; roadbed; in situ plate loading test

\section{INTRODUCTION}

The resilient modulus of the roadbed is one of the most important parameters for designing a new or restoring a soft road surface in case of deformation. The thickness of the road surface layer is determined based on the resilient modulus of the roadbed. Moisture content affects the resilient modulus of the roadbed significantly, as it increases the road surface's deformation causing cracks and subsidence, especially in sandy clay embanked roadbeds which are flooded for long periods. The resilient behavior of cohesive soils (fine-grained soils) related to moisture has been studied for over 40 years. The influence of density and water content on the resilient behavior of Florida subgrade soils was studied in [1], while the subgrade resilient modulus was estimated by using standard tests in [2]. The degree of saturation affecting the resilient modulus of Tennessee soils was studied in [3]. An improved evaluation procedure of roadbed soil's resilient modulus was introduced in [4]. The effect of moisture on the resilient modulus of the Ohio roadbed was investigated in [5]. In [6], a correlation between the relative moisture and the resilient modulus of the roadbed was proposed. The elastic and deformation characteristics of bottom ash in road construction, in particular Young's modulus and Poisson's ratio, were studied in [7]. According to [8], the settlement response of the embankment dam was similar for the Mohr-Coulomb and the Hardening Soil Models for three material zones (clay core, sandy gravel, and random fill), having a modulus of elasticity in the range $25000-50000 \mathrm{kPa}$. These studies showed that the resilient modulus of soil embanked roadbed depends heavily on soil type, moisture content, and soil condition [9].

The current study carried out laboratory experiments to observe the effects of moisture and fine grain content on the resilient modulus of a sandy clay embankment roadbed in the Mekong Delta of Vietnam.

\section{MATERIALS AND METHODS}

\section{A. Determination of the Resilient Modulus}

The resilient modulus is determined based on elastic strain. In road constructions, it is used to calculate the roadbed and road surface subsidence. Due to the transient workload, the loading and unloading time is extremely fast and repeated, while after several loads the accumulated plastic strain is reduced or eliminated. The subsidence of road works depends heavily on the elastic strain of the roadbed and road surface structure. Resilient modulus is defined, according to [10], as:

$$
M_{r}=\left(\sigma_{1}-\sigma_{3}\right) / \varepsilon_{r}=\sigma_{d} / \varepsilon_{r}
$$

where $\sigma_{1}$ and $\sigma_{3}$ are the major and minor principal stresses, $\sigma_{d}$ is the deviator stress, and $\varepsilon_{r}$ is the accumulated plastic strain.

\section{B. Factors Affecting Resilient Modulus}

It has been shown that the resilient modulus of cohesive soil depends on soil type, moisture content, saturation, the content of the grains that can go through the No.200 sieve, deflection stress, suction force, plasticity index, pore water 
pressure, lateral pressure, and lateral compression strength [1130].

\section{Effect of Moisture Content on the Resilient Modulus}

Moisture content is the main parameter affecting the resilient modulus of sandy clay, as in low moisture the water binds soil grains and increases the effective stress between them through its suction and surface tension, leading to high resilient modulus values. Moreover, at low moisture content, the sandy clay produces strong suction in water enough to reproduce a significant temporary colloidal effect between soil grains. Increased moisture damages this phenomenon. The state of sandy clay depends heavily on water capacity, namely the physical bonding layers of water surrounding the coarse soil grains. When the soil is completely dry, the corresponding state is extremely hard or solid, the deformation is negligible, and the resilient modulus of the sandy clay increases due to the attraction between the opposite ions. Moisture content increases gradually with a strong water suction layer, increasing effective stress between soil grains through the suction and the surface tension of water. However, the soil sample volume remains unchanged until the grains are fully deposited in the water suction layer, the soil volume begins to increase due to the thickness of the water shells, the water takes up the voids that push the soil grains apart, the surface suction force decreases, the soil's resilient modulus value decreases, the soil becomes semi-hard and flexible, and when free water appears, the resilient modulus gradually decreases as the soil turns into the liquid state. Too much water causes the soil to enter a suspension state [31]. The resilient modulus value of the sample with the optimum moisture content is much greater than the resilient modulus value of the saturated sample.

\section{Effect of Fine-Grained Content on Resilient Modulus}

The resilient modulus of a cohesive embankment roadbed depends on the type of cohesive soil. The grain content is also an important factor affecting the resilient modulus of cohesive soils, especially the percentage of the grains that can go through the No. 200 sieve. When moisture is low, water binds soil grains (especially of fine-grained soil) and increases the effective stress between soil grains through the suction and the surface tension of water. In this case, the deformation of the soil is negligible. The clay may crack and become extremely hard when it is dry. Moisture gradually increases until the grains are fully deposited into the water suction layer, the soil volume begins to increase due to the thickness of water shells, the water takes up the hollow holes pushing the soil grains apart, and the soil becomes semi-hard and flexible [31, 32].

\section{E. Laboratory Experiments}

\section{1) Purpose}

The main purpose of the experiments was to identify the physical characteristics of moisture content, saturation, unconfined compressive strength, plasticity index, liquid limit, optimum moisture, and the content of grains finer than $0.075 \mathrm{~mm}$. The rapid compression test utilized a 3 -axis compression chamber to determine the resilience of the soil samples and calculate the resilient modulus. A total of 124 rapid compression tests were conducted to determine the resilient modulus, while 30 experiments were conducted to determine the physical characteristics and the grain content of the soil.

\section{2) Standards and Methods}

The soil samples were sandy clay samples with different moisture values. Soil samples were collected from the trunks of roads in annually flooded areas and classified according to AASHTO M 145-91 [33] based on grain composition and Atterberg limit. The resilient modulus was determined according to AASHTO T294-03 [34]. The simulation of vehicle load was performed on soil samples at 6 moisture values $(2 \%$ and $3 \%$ dryer than the optimum, the optimum, $2 \%$ and $3 \%$ over the optimum, completely saturated). Liquid limit and plasticity index were determined according to AASHTO T89-07 [35] and T90-10 [36], while the grain content was analyzed according to AASHTO T88-04 [37]. The maximum dry density and the optimum moisture were determined according to AASHTO T180-01 [38], while the moisture was determined according to AASHTO T265-04 [39].

\section{3) Sample Collection and Experimentation}

Thirty soil samples were collected at $30 \mathrm{~cm}$ depth in the road body of the annually flooded roads in Dong Thap, Long An, and Tien Giang provinces. The natural moisture content of the samples was $9.9-32.7 \%$. The basic physical characteristics of the samples were determined, including liquid limit, plasticity limit, grain content, standard compaction, and unconfined compressive strength. Table I shows the results of liquid limit, plastic limit, and grain content analysis.

TABLE I. GRAIN CONTENT AND ATTERBERG LIMIT OF SAMPLES

\begin{tabular}{|c|c|c|c|c|c|c|}
\hline No. & Sample & $\begin{array}{c}\text { Liquid } \\
\text { limit }\end{array}$ & $\begin{array}{l}\text { Plasticity } \\
\text { index }\end{array}$ & $\begin{array}{l}\text { Sand } \\
(\%)\end{array}$ & $\begin{array}{l}\text { Dust } \\
(\%)\end{array}$ & $\begin{array}{l}\text { Clay } \\
(\%)\end{array}$ \\
\hline 1 & LA842.1 & 33.0 & 14.8 & 15.2 & 48.9 & 33.9 \\
\hline 2 & LA842.2 & 34.3 & 12.1 & 12.4 & 48.9 & 35.9 \\
\hline 3 & LA842.3 & 39.7 & 14.6 & 14.0 & 49.8 & 35.4 \\
\hline 4 & DT942.1 & 39.6 & 12.0 & 16.6 & 45.4 & 35.1 \\
\hline 5 & DT942.2 & 36.0 & 11.3 & 17.7 & 43.0 & 32.1 \\
\hline 6 & DT942.3 & 38.3 & 11.6 & 15.3 & 43.5 & 39.8 \\
\hline 7 & DT942.4 & 39.0 & 11.9 & 21.5 & 38.4 & 34.8 \\
\hline 8 & DT942.5 & 38.8 & 11.6 & 10.8 & 53.4 & 34.6 \\
\hline 9 & DT942.6 & 35.3 & 11.4 & 10.7 & 50.9 & 31.6 \\
\hline 10 & DT942.7 & 39.7 & 11.5 & 5.2 & 54.4 & 38.6 \\
\hline 11 & DT942.8 & 38.2 & 11.8 & 15.7 & 51.9 & 31.9 \\
\hline 12 & DT942.9 & 39.6 & 11.6 & 11.3 & 44.2 & 39.2 \\
\hline 13 & DT942.10 & 39.9 & 11.7 & 7.3 & 55.1 & 36.2 \\
\hline 14 & DT847.1 & 38.3 & 12.4 & 14.0 & 49.4 & 36.2 \\
\hline 15 & DT847.2 & 38.9 & 11.5 & 10.6 & 53.8 & 35.2 \\
\hline 16 & DT847.3 & 38.8 & 11.3 & 12.6 & 43.4 & 41.4 \\
\hline 17 & DT847.4 & 39.9 & 11.5 & 16.9 & 42.4 & 38.1 \\
\hline 18 & DT847.5 & 39.5 & 16.4 & 24.8 & 38.7 & 33.6 \\
\hline 19 & DT847.6 & 39.4 & 15.3 & 34.5 & 30.1 & 31.6 \\
\hline 20 & DT847.7 & 39.4 & 15.3 & 16.6 & 45.2 & 33.7 \\
\hline 21 & DT847.8 & 38.0 & 13.8 & 27.1 & 36.5 & 33.7 \\
\hline 22 & DT847.9 & 38.4 & 13.2 & 13.8 & 50.1 & 35.1 \\
\hline 23 & DT847.10 & 37.3 & 12.3 & 19.7 & 38.2 & 37.3 \\
\hline 24 & DT847.11 & 38.3 & 12.0 & 20.5 & 46.6 & 32.6 \\
\hline 25 & DT847.12 & 39.1 & 11.6 & 20.0 & 47.6 & 31.6 \\
\hline 26 & DT847.13 & 38.0 & 14.8 & 33.9 & 31.2 & 31.2 \\
\hline 27 & DT867.1 & 38.2 & 13.3 & 33.9 & 29.1 & 33.1 \\
\hline 28 & DT867.2 & 39.0 & 11.6 & 23.5 & 33.7 & 37.3 \\
\hline 29 & DT867.3 & 38.8 & 13.3 & 42.2 & 22.9 & 31.2 \\
\hline 30 & DT867.4 & 39.0 & 12.1 & 36.8 & 29.5 & 32.5 \\
\hline
\end{tabular}


An unconfined compressive strength test, according to AASHTO T208-05 [40], was carried out with a speed of $1 \mathrm{~mm} / \mathrm{min}$ right after compressing the sample to determine the value of the resilient modulus. The unconfined compressive strength was determined from the stress-strain curve. It is the maximum compressive stress value that the sample has to withstand or the value corresponding to $20 \%$ strain if this case happens first. Axial compressive stress $\sigma_{l} \quad(\mathrm{kPa})$ was determined by:

$$
\sigma_{1}=\left[\frac{P(1-\varepsilon)}{A_{0}}\right] \times 100
$$

\section{F. Determining the Resilient Modulus of the Soil}

The purpose of this test was to measure the resilient strain of the soil samples under the effect of fast compressive loading and determine the influence level of moisture and grains with a finer than $0.075 \mathrm{~mm}$ size on the resilient modulus. For each soil sample collected, $15 \mathrm{~kg}$ were selected through a $5 \mathrm{~mm}$ sieve, they were divided into 6 equal weight parts, placed into 6 trays, and 6 different water quantities were sprayed on them to obtain the required moisture levels: $2 \%$ and $3 \%$ drier than the optimum, the optimum, $2 \%$ and $3 \%$ wetter than the optimum, and one saturated. Wet soil was mixed, covered with a damp cloth, and incubated for $12 \mathrm{~h}$. The preparation of a test sample $m(\mathrm{~g})$ with the desired moisture value $W(\%)$ requires the determination of the moisture content of the sample $W_{l}(\%)$ and the calculation of the amount of water $q(\mathrm{~g})$ to be sprayed according to:

$$
q=\left[0.01 m /\left(1+0.01 W_{1}\right)\right] \times\left(W-W_{1}\right)
$$

A compacting mortar with $125 \mathrm{~mm}$ diameter and $127 \mathrm{~mm}$ height was placed on a hard and leveled ground. The prepared soil was taken into the mortar with 3 layers, each one occupying about $1 / 3$ of the mortar's volume. A $2.5 \mathrm{~kg}$ hammer was used on free fall from a height of $300 \mathrm{~mm}$, evenly distributed over the surface of the soil layer. Each layer was compacted with 40 hammer drops. The compacted soil was removed from the mortar by pressing a cutting ring, having $36 \mathrm{~mm}$ diameter and $76 \mathrm{~mm}$ height, vertically into the core of the soil. The cutting ring was removed from the soil by whittling. The removed sample was weighted to determine its natural volume and placed in a rubber wrap. A 3-axis compression device model 28-T0401, shown in Figure 1, was used to perform the tests.

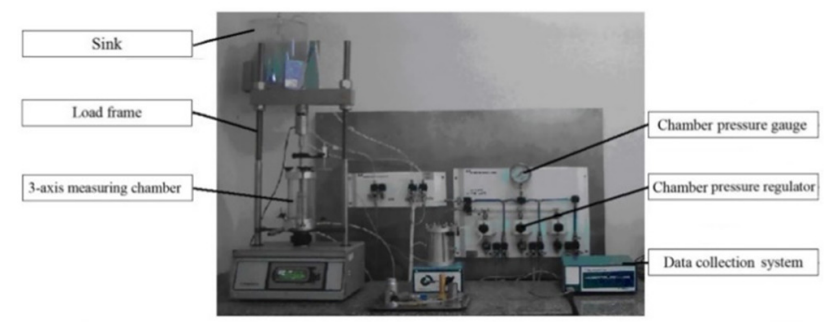

Fig. 1. The triaxial compression device system.

The prepared samples were placed in the laboratory chamber to eliminate the residual strain by applying lateral and vertical pressure. By loading and unloading many times with a strain rate of $1 \mathrm{~mm} / \mathrm{min}$, the sample accumulated the residual strain until there was only resilient strain left. The water inlet valve was opened until the chamber was full. Three levels of lateral pressure were applied $(41,21$, and $0 \mathrm{kPa})$ with 5 deviator stress levels $(14,28,41,55$, and $69 \mathrm{kPa})$. During the experiment, the bottom drain valve was unlocked. The results of loading for an unsaturated sample (DT.942.7-2) are shown in Figure 2.

TABLE II. LOADS ON UNSATURATED SAMPLE

\begin{tabular}{|c|c|c|c|c|}
\hline No. & $\begin{array}{c}\text { Lateral } \\
\text { pressure } \boldsymbol{\sigma}_{3} \\
(\mathbf{k P a})\end{array}$ & $\begin{array}{c}\boldsymbol{\sigma}_{\boldsymbol{d}} \\
\mathbf{( k P a )}\end{array}$ & $\begin{array}{c}\text { Times of } \\
\text { loading (times) }\end{array}$ & Note \\
\hline 0 & 0 & 69 & Many times & $\begin{array}{c}\text { Residual strain } \\
\text { elimination }\end{array}$ \\
\hline 1 & 41 & 14 & 3 & $\begin{array}{c}\text { Get the average } \\
\text { value }\end{array}$ \\
\hline 2 & 41 & 28 & 3 & \\
\hline 3 & 41 & 41 & 3 & \\
\hline 4 & 41 & 55 & 3 & \\
\hline 5 & 41 & 69 & 3 & \\
\hline 6 & 21 & 14 & 3 & \\
\hline 7 & 21 & 28 & 3 & \\
\hline 8 & 21 & 41 & 3 & \\
\hline 9 & 21 & 55 & 3 & \\
\hline 10 & 21 & 69 & 3 & \\
\hline 11 & 0 & 14 & 3 & \\
\hline 12 & 0 & 28 & 3 & \\
\hline 13 & 0 & 41 & 3 & \\
\hline 14 & 0 & 55 & 3 & \\
\hline 15 & 0 & 69 & 3 & \\
\hline 16 & 0 & Destroy the & & \\
\hline
\end{tabular}

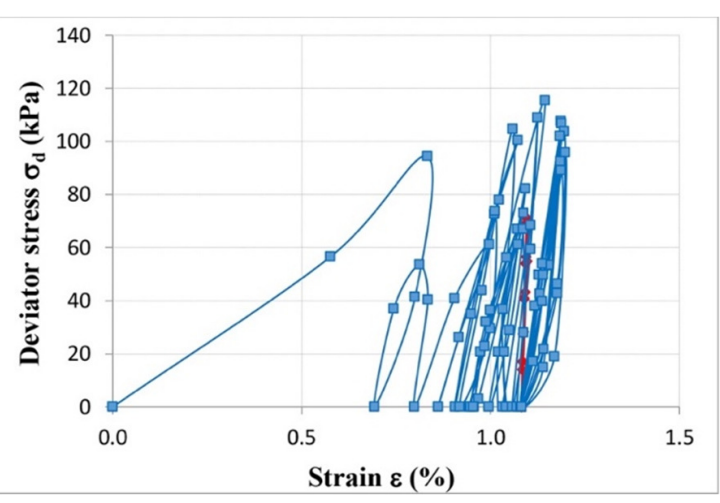

Fig. 2. Results of loading with unsaturated soil samples (DT.942.7-2).

In each deviator stress level test, it was necessary to load and unload 3 times to get the average of the deviator stresses corresponding to the average of the resilient strain. Figure 3 shows the deviator stress-resilient strain relationship of the sample. The average values of the deviator stress and resilient strain can be used to calculate the resilient modulus value according to (4). The resilient strain generated after each load level consists of two resilient strain parts: an instant resilient strain part generated when the load is applied to the soil and another due to the rheological behavior in load time. Slower speeds of loading (on the road when the car is running slower) cause greater resilient strains, as shown in Figure 4. Similar resilient values cause different $P$ loads, resulting in different soil resilient modulus. 


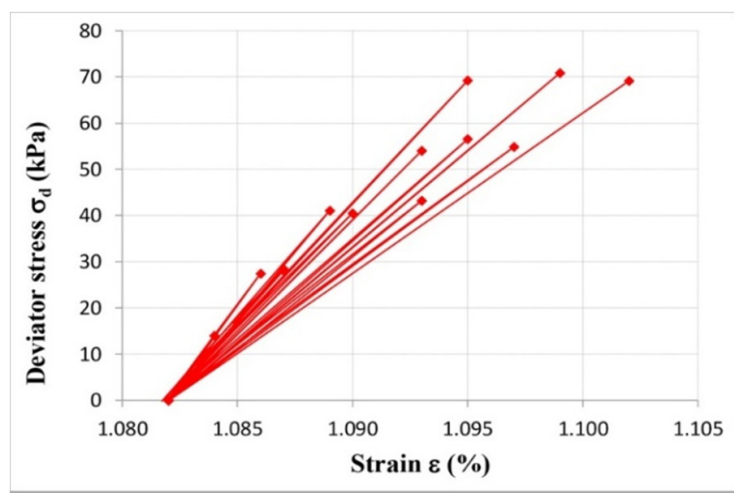

Fig. 3. The relationship of $\sigma_{d}$ with the resilient strain $\sigma_{3}$ is unchanged (DT.942.7-2)

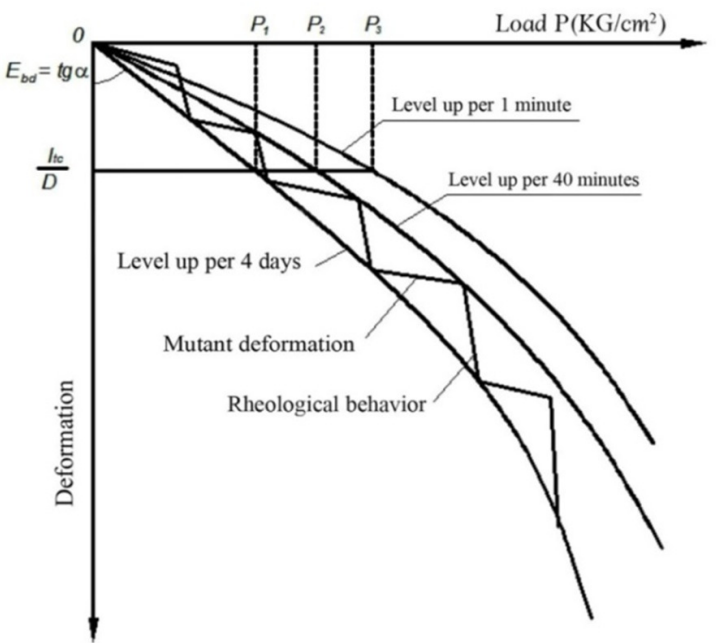

Fig. 4. The resilient strain curve of the compressing test when the load increases with each level at a uniform speed.

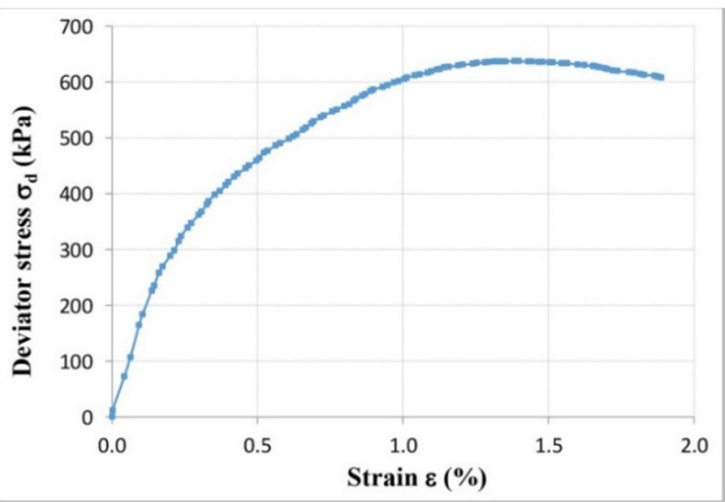

Fig. 5. Determining the unconfined compressive strength (DT.942.7-2).

The unconfined compressive strength test was carried out immediately after the completion of five deviator stress levels, with zero lateral pressure and vertical load at $1 \mathrm{~mm} / \mathrm{min}$ until the sample was damaged to determine the compressive strength $q_{u}$. Figure 5 shows a strain graph for determining $q_{u}$ of $637.2 \mathrm{kPa}$ for sample DT942.7-2 having $15.7 \%$ moisture content. The unconfined compressive strength of the test samples was between 60.6 and $774.3 \mathrm{kPa}$. The correlation coefficient between the resilient modulus and the unconfined compressive strength $\left(q_{u}\right)$ was $0.6788\left(R^{2}\right)$. For saturated samples, the test was only performed with zero lateral pressure level and five levels of deviator stress: $14,28,41,55,69 \mathrm{kPa}$. During the experiment, the bottom drain valve was locked. The loading method for saturated samples is shown in Table III, and the results of loading for the saturated samples (DT.942.7-5) are shown in Figure 5.

TABLE III. LOAD ON SATURATED SAMPLES

\begin{tabular}{|c|c|c|c|c|}
\hline No. & $\begin{array}{c}\text { Lateral pressure } \boldsymbol{\sigma}_{3} \\
(\mathbf{k P a})\end{array}$ & $\boldsymbol{\sigma}_{\boldsymbol{d}} \mathbf{( k P a )}$ & $\begin{array}{c}\text { Times of loading } \\
(\text { times })\end{array}$ & Note \\
\hline 1 & 0 & 14 & 3 & \\
\hline 2 & 0 & 28 & 3 & \\
\hline 3 & 0 & 41 & 3 & \\
\hline 4 & 0 & 55 & 3 & Determine \\
\hline 5 & 0 & 69 & 3 & $q_{u}$ \\
\hline 6 & 0 & $\begin{array}{c}\text { Destroy the } \\
\text { sample }\end{array}$ & & \\
\hline
\end{tabular}

The resilient modulus determined from a 3-axis compression test is the ratio of the deviator stress and the relative resilient strain of the sample:

$$
\begin{gathered}
M_{r}=\sigma_{d} / \varepsilon \\
\sigma_{d}=\sigma_{1}-\sigma_{3} \\
\varepsilon=\Delta h / h
\end{gathered}
$$

The resilient strain of soil samples was recorded by the data collection system according to each load level. It was necessary to choose the average resilient strain value of the three load times for each load level to calculate the resilient modulus.

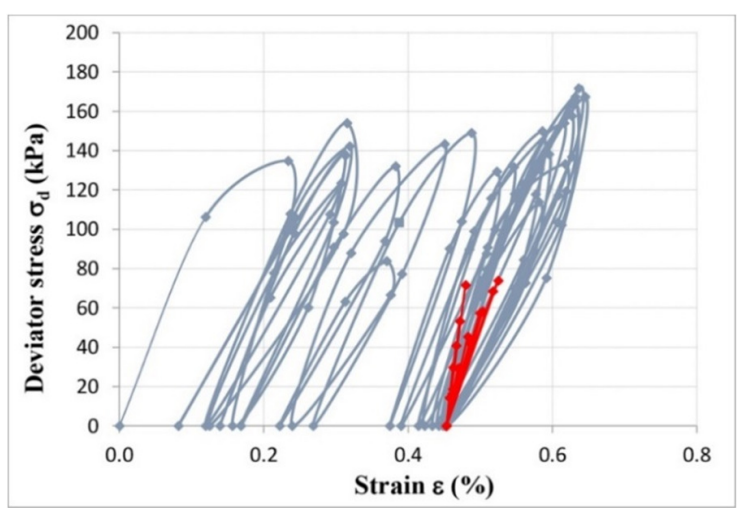

Fig. 6. Load result of unsaturated soil samples (DT.942.7-5).

\section{RESULTS AND DISCUSSION}

Figures 7-9 show the experimental results for the resilient modulus of the 30 soil samples. In Figure 7, a lateral pressure of $41 \mathrm{kPa}$ was applied during the experiment, with 5 samples having moisture content of $14.5 \%, 15.7 \%, 17.4 \%, 19.6 \%$, and $20.3 \%$. Five deviator stress levels were performed to determine the resilient modulus, at 14, 28, 41, 55, and $69 \mathrm{kPa}$. Figures 8 and 9 show similar experiments by applying lateral pressures of 21 and $0 \mathrm{kPa}$ respectively. The results illustrate the effect of moisture content, deviator stress, and lateral pressure on the resilient modulus. The resilient modulus is significantly affected by moisture content, as it decreased as the moisture 
content increased at constant lateral pressure level. The resilient modulus decreased as the deviator stress increased, tending to change nonlinearly with the deviator stress at the same lateral pressure level. The resilient modulus increased as the lateral pressure increased at the optimum moisture value and the same level of deviator stress. The resilient modulus of the saturated samples decreased by $24.8-56.6 \%$ from the optimum moisture content. The correlation coefficient $\left(R^{2}\right)$ between the resilient modulus and moisture was 0.8849 . The $R^{2}$ between the resilient modulus and saturation was 0.6741 .

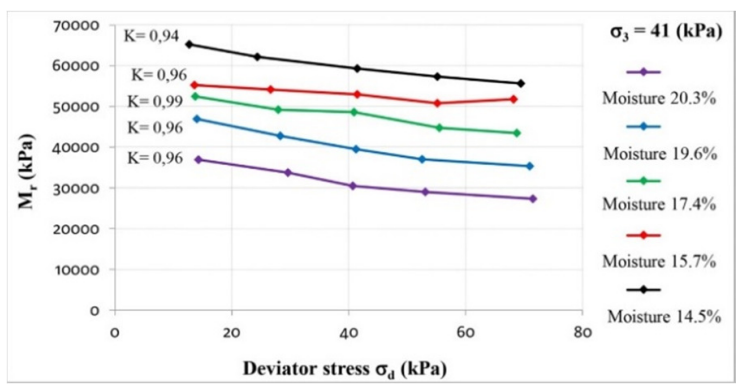

Fig. 7. $M_{r}$ according to moisture and deviator stress, lateral pressure $41 \mathrm{kPa}$ (model DT942.7).

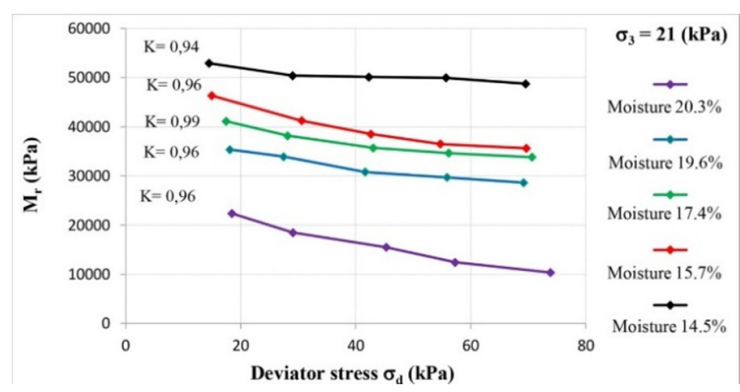

Fig. 8. $M_{r}$ according to moisture and deviator stress, lateral pressure $21 \mathrm{kPa}$ (model DT942.7).

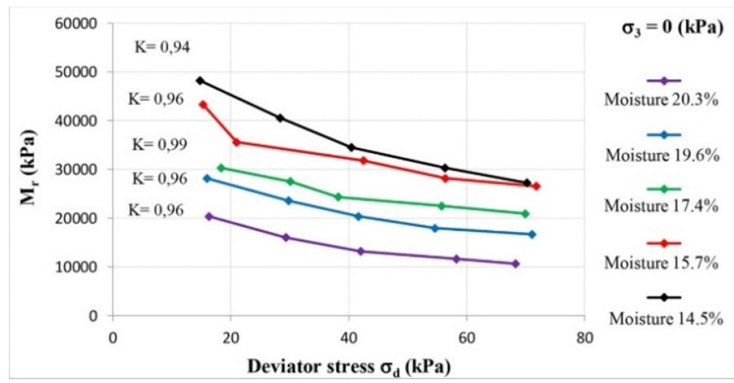

Fig. 9. $\quad M_{r}$ according to moisture and deviator stress, lateral pressure $0 \mathrm{kPa}$ (model DT942.7).

Figure 10 shows the effect of the grain content with a size finer than $0.075 \mathrm{~mm}$ on the variation rate of resilient modulus due to the change of moisture content. The content of grains with size finer than $0.075 \mathrm{~mm}$ varied from $54.1 \%$ (sample DT.867.4) to $93.0 \%$ (sample DT.942.7), while the value of the resilient modulus varied from $53.7 \%(60,548-28,043 \mathrm{kPa})$ to $89.1 \%(95,533-10,426 \mathrm{kPa})$. The more the content of grains having size finer than $0.075 \mathrm{~mm}$ was, the more it affected the variation ratio of the resilient modulus. The content of grains having size finer than $0.075 \mathrm{~mm}$ accounts for $54.1 \%$ (sample DT.867.4) to $70.1 \%$ (sample DT.847.10) corresponding to the rate of value variation of the resilient modulus from $53.7 \%$ $(60,548-28,043 \mathrm{kPa})$ to $65.6 \%(45,531-15,681 \mathrm{kPa})$. The content of grains having size finer than $0.075 \mathrm{~mm}$ accounts from $72.3 \%$ (sample DT.867.6) to $93.0 \%$ (sample DT.942.7) corresponding to the variation rate value of the resilient modulus from $65.8 \%(48,903-16,709 \mathrm{kPa})$ to $89.1 \%(95,533-$ $10,426 \mathrm{kPa})$. The $R^{2}$ between the resilient modulus and the content of grains having a size finer than $0.075 \mathrm{~mm}$ was 0.7358 . The correlation coefficient between the resilient modulus and plasticity index was 0.5412 .

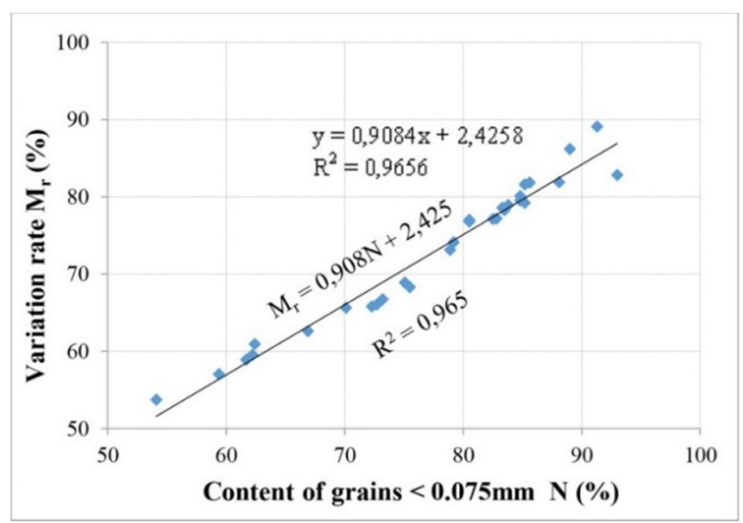

Fig. 10. Effect the content of grains having size finer than $0.075 \mathrm{~mm}$ on $M_{r}$.

The obtained results demonstrate that the resilient modulus is significantly influenced by moisture and the content of grains having size finer than $0.075 \mathrm{~mm}$. The increased moisture content of the sample caused a drop in the resilient modulus. In many cases, the resilient modulus value of the saturated samples was reduced by more than $56.6 \%$ (35,698 $15,489 \mathrm{kPa}$ ) compared to the samples at optimum moisture content. The resilient modulus decreased nonlinearly when the deflection stress increased. Increasing lateral pressure led to an increase in the resilient modulus of the soil sample. The higher the percentage of clay grains, the larger the area they cover, and the greater the resilient modulus of the soil is due to the attraction between opposite ions. The increased moisture corresponds to the thickness of the water shells. The greater the volume of water that occupies the voids, the farther apart the soil grains are, and the lower the surface suction of soil grains decreases. Thus, the resilient modulus of the soil decreases significantly.

\section{CONCLUSIONS}

The resilient modulus was significantly affected by the moisture content, as it decreased rapidly as the moisture content increased by $1-2 \%$. The resilient modulus for saturated samples was reduced by $56.6 \%$ in comparison to the optimum moisture content (sample DT942.7). The resilient modulus reached the smallest value of $8.153 \mathrm{kPa}$ when the sample had a moisture content of $23.3 \%$ and the content of grains having size finer than $0.075 \mathrm{~mm}$ accounted for $88.1 \%$ (sample DT942.5). The percentage of grains having size finer than $0.075 \mathrm{~mm}$ of the 
soil sample had an important influence on the value of the resilient modulus. Among the tested samples, those with a higher proportion of grains with size finer than $0.075 \mathrm{~mm}$ had a greater drop of resilient modulus value with increased moisture, while their resilient modulus reached the smallest values on the maximum moisture. The percentage of grains having size finer than $0.075 \mathrm{~mm}$ in the samples was between 54.1 and $79.2 \%$. The resilient modulus varied with moisture content from $53.7 \%$ to $89.1 \%$. The greater the percentage of grains that are finer than $0.075 \mathrm{~mm}$ is, the higher the ratio, the larger the area ratio, the greater the water absorption capacity, and the more the resilient modulus decreases.

\section{REFERENCES}

[1] M. K. Elfino and J. L. Davidson, "Modeling Field Moisture in Resilient Moduli Testing," in Resilient Moduli of Soils: Laboratory Conditions, David. J. Elton, Ed. New Orleans, Louisiana, USA: ASCE, 1989, pp. 31-51.

[2] E. C. Drumm, Y. Boateng Poku, and T. Johnson Pierce, "Estimation of Subgrade Resilient Modulus from Standard Tests," Journal of Geotechnical Engineering, vol. 116, no. 5, pp. 774-789, May 1990, https://doi.org/10.1061/(ASCE)0733-9410(1990)116:5(774).

[3] E. C. Drumm, J. S. Reeves, M. R. Madgett, and W. D. Trolinger, "Subgrade Resilient Modulus Correction for Saturation Effects," Journal of Geotechnical and Geoenvironmental Engineering, vol. 123, no. 7, pp. 663-670, Jul. 1997, https://doi.org/10.1061/(ASCE)1090-0241(1997) 123:7(663).

[4] L. N. Mohammad, H. H. Titi, and A. Herath, "Evaluation of Resilient Modulus of Subgrade Soil by Cone Penetration Test," Transportation Research Record, vol. 1652, no. 1, pp. 236-245, Jan. 1999, https://doi.org/10.3141/1652-30.

[5] D. G. Kim, "Development of a constitutive model for resilient modulus of cohesive soils," Ph.D. dissertation, Civil Engineering, The Ohio State University, Columbus, OH, USA, 2004.

[6] D. C. Hai and X. T. Nguyen, Road Design. Education Publisher, 2012.

[7] V. T. Phan and T. T. H. Nguyen, "Elastic and Deformation Characteristics of MSWI Bottom Ash for Road Construction," Engineering, Technology \& Applied Science Research, vol. 10, no. 6, pp. 6389-6392, Dec. 2020, https://doi.org/10.48084/etasr.3817.

[8] A. H. Bhutto et al., "Mohr-Coulomb and Hardening Soil Model Comparison of the Settlement of an Embankment Dam," Engineering, Technology \& Applied Science Research, vol. 9, no. 5, pp. 4654-4658, Oct. 2019, https://doi.org/10.48084/etasr.3034.

[9] H. L. Wang et al., "Effects of inclusion contents on resilient modulus and damping ratio of unsaturated track-bed materials," Canadian Geotechnical Journal, May 2017, https://doi.org/10.1139/cgj-20160673.

[10] Y. H. Huang, Pavement analysis and design. Englewood Cliffs, NJ, USA: Prentice-Hall, 1993.

[11] D.-S. Kim and S. Drabkin, "Accuracy improvement of external resilient modulus measurements using specimen grouting to end platens," Transportation Research Record, no. 1462, pp. 65-71, 1994.

[12] T. Y. Chu, S. N. Chen, S. S. Guram, R. L. Stewart, and W. K. Humphries, "Soil Moisture as a Factor in Subgrade Evaluation," Transportation Engineering Journal of ASCE, vol. 103, no. 1, pp. 87102, Jan. 1977, https://doi.org/10.1061/TPEJAN.0000625.

[13] G. B. Thadkamalla and K. P. George, "Characterization of subgrade soils at simulated field moisture," Characterization of subgrade soils at simulated field moisture, no. 1481, pp. 21-27, 1995.

[14] R. P. Elliott and S. I. Thornton, "Simplification of subgrade resilient modulus testing," Transportation Research Record, no. 1192, pp. 1-7, 1988.

[15] R. Pezo and W. R. Hudson, "Prediction Models of Resilient Modulus for Nongranular Materials," Geotechnical Testing Journal, vol. 17, no. 3, pp. 349-355, Sep. 1994, https://doi.org/10.1520/GTJ10109J.
[16] J. M. Burczyk, K. Ksaibati, R. Anderson-Sprecher, and M. J. Farrar, "Factors infuencing determination of a subgrade resilient modulus value," Transportation Research Record, no. 1462, pp. 72-78, 1994.

[17] M. R. Thompson and Q. L. Robnett, "Resilient Properties of Subgrade Soils," Transportation Engineering Journal of ASCE, vol. 105, no. 1, pp. 71-89, Jan. 1979, https://doi.org/10.1061/TPEJAN.0000772.

[18] G. Rada and M. W. Witczak, "Comprehensive evaluation of laboratory resilient moduli results for granular material," Transportation Research Record, no. 810, pp. 23-33, 1981.

[19] D. Li and E. T. Selig, "Resilient Modulus for Fine-Grained Subgrade Soils," Journal of Geotechnical Engineering, vol. 120, no. 6, pp. 939957, Jun. 1994, https://doi.org/10.1061/(ASCE)0733-9410(1994)120: 6(939).

[20] D. G. Fredlund, A. T. Bergan, and P. K. Wong, "Relation between resilient modulus and stress conditions for cohesive subgrade soils," Transportation Research Record, no. 642, pp. 73-81, 1977.

[21] R. Zhang, T. Ren, M. A. Khan, Y. Teng, and J. Zheng, "BackCalculation of Soil Modulus from PFWD Based on a Viscoelastic Model," Advances in Civil Engineering, vol. 2019, p. e1316341, Nov. 2019, https://doi.org/10.1155/2019/1316341.

[22] W. T. Oh and S. Vanapalli, "Modelling the stress versus displacement behavior of shallow foundations in unsaturated coarse-grained soils," Deformation Characteristics of Geomaterials, pp. 821-828, 2011, https://doi.org/10.3233/978-1-60750-822-9-821.

[23] S. K. Vanapalli and F. M. O. Mohamed, "Bearing Capacity of Model Footings in Unsaturated Soils," in Experimental Unsaturated Soil Mechanics, Berlin, Heidelberg, Germany: Springer, 2007, pp. 483-493, https://doi.org/10.1007/3-540-69873-6_48.

[24] W. T. O. T. Oh, S. K. V. K. Vanapalli, and A. J. P. J. Puppala, "Semiempirical model for the prediction of modulus of elasticity for unsaturated soils," Canadian Geotechnical Journal, Jul. 2009, https://doi.org/10.1139/T09-030.

[25] W. V. Ping and L. Ge, "Field Verification of Laboratory Resilient Modulus Measurements on Subgrade Soils," Transportation Research Record, vol. 1577, no. 1, pp. 53-61, Jan. 1997, https://doi.org/ 10.3141/1577-07.

[26] Y. Yao, J. Qian, J. Li, A. Zhang, and J. Peng, "Calculation and Control Methods for Equivalent Resilient Modulus of Subgrade Based on Nonuniform Distribution of Stress," Advances in Civil Engineering, vol. 2019, Sep. 2019, Art. no. e6809510, https://doi.org/10.1155/2019/ 6809510.

[27] L. Raad and B. A. Zeid, "Repeated load model for subgrade soils: model development," Transportation Research Record, no. 1278, pp. 72-82, 1990.

[28] M. R. Thompson and Q. L. Robnett, "Resilient Properties of Subgrade Soils," Transportation Engineering Journal of ASCE, vol. 105, no. 1, pp. 71-89, Jan. 1979, https://doi.org/10.1061/TPEJAN.0000772.

[29] L. N. Mohammad, H. H. Titi, and A. Herath, "Intrusion technology: An innovative approach to evaluate resilient modulus of subgrade soils," presented at the Application of Geotechnical Principles in Pavement Engineering, Proceedings of Sessions of Geo-Congress 98American Society of Civil Engineers, Boston, MA, USA, 1998.

[30] A. M. Rahim and K. P. George, "Automated Dynamic Cone Penetrometer for Subgrade Resilient Modulus Characterization," Transportation Research Record, vol. 1806, no. 1, pp. 70-77, Jan. 2002, https://doi.org/10.3141/1806-08.

[31] K. P. George, "Prediction of resilient modulus from soil index properties," Department of Civil Engineering, University of Mississipi, Final report FHWA/MS-DOT-RD-04-172, Aug. 2004.

[32] R. F. Carmichael III and E. Stuart, "Predicting resilient modulus: a study to determine the mechanic properties of subgrade soils (abridgment)," Transportation Research Record, no. 1043, pp. 145-148, 1985.

[33] Standard Specification for Classification of Soils and Soil-Aggregate Mixtures for Highway Construction Purposes, AASHTO M 145-91, American Association of State Highway and Transportation Officials, 1991.

[34] Standard Method of Test for Resilient Modulus of Subgrade Soils and Untreated Base/Subbase Materials - SHRP Protocol P46, AASHTO 
T294-03, American Association of State Highway and Transportation Officials, 2003.

[35] Determining the Liquid Limit of Soils, AASHTO T89-07, American Association of State Highway and Transportation Officials, 2007.

[36] Determining the Plastic Limit and Plasticity Index of Soils, AASHTO T90-10, American Association of State Highway and Transportation Officials, 2010.

[37] Standard Method of Test for Particle Size Analysis of soils, AASHTO T88-04, American Association of State Highway and Transportation Officials, 2004.

[38] Standard Method of Test for Moisture-Density Relations of Soils Using a 4.54-kg (10-lb) Rammer and a 457-mm (18-in.) Drop, AASHTO T18001, American Association of State Highway and Transportation Officials, 2001.

[39] Standard Method of Test for Laboratory Determination of Moisture Content of Soils, AASHTO T265-04, American Association of State Highway and Transportation Officials, 2004.

[40] Standard Method of Test for Unconfined Compressive Strength of Cohesive Soil, AASHTO T208-05, American Association of State Highway and Transportation Officials, 2005. 